\title{
Effect on appetite control of minor cereal and pseudocereal products
}

\author{
Cristiana Berti*, Patrizia Riso, Antonella Brusamolino and Marisa Porrini \\ Department of Food Science and Microbiology, Division of Human Nutrition, University of Milan, Milan, Italy \\ (Received 17 January 2005 - Revised 10 June 2005 - Accepted 9 July 2005)
}

\begin{abstract}
Recent findings suggest that Western diets based on highly palatable foods are likely to be much less satiating than more traditional diets or those typical of less developed countries. In particular, some alternative crops (for example, buckwheat, oat, barley, spelt, rye, quinoa, amaranth) seem to be of great nutritional interest and to represent important recipes for healthier and typical regional foods. The objective of the present study was to investigate the effect on subsequent food intake and feelings of satiety of alternative oat bread, oat and buckwheat pasta and of quinoa as compared with their wheat counterparts and rice, respectively. Three different experiments (one specific for each alternative crop food) were conducted, all with a within-subjects design. The preloading paradigm strategy was used. Results showed that preload energy level influenced total energy intake (preload plus ad libitum test meal intake), larger preloads inducing more eating than smaller preloads. No effect of formulation was observed on energy intake, as the consumption of alternative crop formulations did not decrease the total energy intake as compared with that of the counterparts. Satiating efficiency indices (SEI) for alternative crop foods were higher with respect to traditional cereal foods. In particular, white bread was the least satisfying food (SEI $=0 \cdot 2)$ and the different time of consumption (for lunch or as a snack) did not affect energy intake. In conclusion, oat or buckwheat formulations, and also quinoa, may be exploited for their potential impact on eating behaviour, particularly considering they are good sources of functional substances.
\end{abstract}

Cereals: Pseudocereals: Satiety: Appetite: Eating behaviour

Some foodstuffs may be more effective than others in reducing hunger and subsequent food intake and this may be due in part to the influence of macronutrients upon hunger and satiety (Blundell et al. 1988; Green \& Delargy, 1997; Porrini et al. 1997; De Graaf et al. 1999). A reasonable amount of evidence exists to support that the most satiating foods are high in proteins (Westerterp-Plantega et al. 1999) or carbohydrates (Blundell et al. 1994; Stubbs et al. 2001) or fibres (Delargy et al. 1995, 1997) or water (Holt et al. 1995) (for example, potato, steak, fish, apples, orange, porridge, brown pasta, baked beans).

In particular, high-fibre foods have been shown to be highly satiating (Blundell \& Burley, 1987). In a study by Holt et al. (1999) it was demonstrated that hunger returns at a lower rate after a high-fibre, carbohydrate-rich breakfast than after a lowfibre, carbohydrate-rich meal. On the contrary, refined foods have been associated with increased insulin responses and decreased satiety; brown pasta was more satiating than white pasta, wholemeal and grain bread more than white bread, and porridge and all-bran were more satiating than other breakfast cereals (Holt et al. 1996). Coarse-wheat breads with intact kernels showed a higher satiety score than did white-wheat breads (Holm \& Björck, 1992). Several studies have shown that an increase in the amount of resistant starch in meals promotes a significant reduction in metabolic responses and increases subjective sensations of satiety (Granfeldt et al. 1994; Raben et al. 1994). Collectively, these findings suggest that Western diets based on highly palatable foods are likely to be much less satiating than more traditional diets or those typical of less developed countries based on relatively unrefined foods (Holt et al. 1995, 2001). Moreover, this knowledge has encouraged the food industry to increase the range of available processed carbohydrate foods that have a lower glycaemic response but are more satiating than their counterparts.

At present there is considerable interest in the consumption of alternative crops, such as buckwheat, oat, barley, spelt, rye, quinoa, amaranth, as potential recipes for healthy food production and for special dietary use (diabetes, coeliac disease, phenylketonuria, etc) (Skrabanja et al. 2001a; Størsrud et al. 2003; Di Cagno et al. 2004). Several are considered minor cereals, i.e. under-utilised cereals (for example, spelt, rye, einkorn, millet, oat, etc); others are pseudocereals, crops evolutionarily distant from cereals (Graminaceae), which produce grains (for example, quinoa, amaranth, buckwheat).

The use of these minor cereals and pseudocereals is of great nutritional interest because of their peculiar composition and the minor components present in these grains (dietary fibre, resistant starch, minerals, vitamins, phenols) (Granfeldt et al. 1994; Liljeberg \& Björck, 1994; Gutzmán-Maldonado \& ParedesLopez, 1999; Bonafaccia et al. 2000; Zieliński \& Kozlowska, 2000; Skrabanja et al. 2001b; Abdel-Aal \& Hucl, 2002; Gabrovská et al. 2002; Kim et al. 2004).

In particular, food scientists and biochemists are studying the technological and nutritional properties of these minor cereals and pseudocereals as wheat replacements (Coulter \& Lorenz, 1990; Ranhotra et al. 1995; Hughes et al. 1997; Singh \& Smith, 1997; Bejosano \& Corke, 1999; Valencia et al. 1999; 
Ruales et al. 2002; Bonafaccia et al. 2003; Ogungbenle, 2003; Yilmaz \& Dağhoğlu, 2003). For example, oat and buckwheat flours, and also quinoa, have been suggested to be safe for a gluten-free (GF) diet (Størsrud et al. 2003; Berti et al. 2004a; Di Cagno et al. 2004).

In the present study, three different experiments were scheduled to investigate the effect of alternative crop formulations and their counterparts on specific and general satiety. Each experiment aimed at comparing a typical Italian food or dish with the same food or dish produced with an alternative crop. In particular, in experiment I, oat and white bread were proposed in order to investigate their potential impact when consumed as preloads immediately before a test meal or as snacks $2 \mathrm{~h}$ before a test meal. In experiment II, the effect of different oat, buckwheat and wheat pasta dishes was evaluated when consumed as preloads before a test meal with respect to a test meal alone. In experiment III, the effect of quinoa preloads was compared with rice.

\section{Methods}

\section{Subjects}

Three different panels were selected for this research, one for each experiment. Fifteen healthy male volunteers (age $22 \cdot 8 \pm 2 \cdot 2$ years; BMI $23.1 \pm 3 \cdot 2 \mathrm{~kg} / \mathrm{m}^{2}$ ) participated in the bread study (experiment I), fourteen in the pasta study (age $24.0 \pm 2.6$ years; BMI $23.3 \pm 2.7 \mathrm{~kg} / \mathrm{m}^{2}$ ) (experiment II) and twelve (age $25.4 \pm 2.2$ years; BMI $23.0 \pm 1.9 \mathrm{~kg} / \mathrm{m}^{2}$ ) in the quinoa study (experiment III). All subjects were recruited from the student population of the University of Milan. They were normal weight for height and were not on any medication or taking any drugs. Furthermore, they declared they were not on a restrictive diet. The study was approved by the Faculty of the Agriculture Ethical Committee.

The recruitment of the volunteers was conducted using data from a questionnaire on subjective eating habits and food preferences (none, normal, high) for ninety-eight foods. The selected subjects had a normal preference for the foods included in the study.

\section{Foods}

White bread (regular bread), oat bread (40\% toasted oats), spaghetti (regular spaghetti), oat spaghetti ( $40 \%$ toasted oats), lasagne (regular fresh pasta; $20 \%$ egg), carboxymethyl cellulose buckwheat lasagne $(60 \%$ buckwheat and $40 \%$ precooked rice flour, $30 \%$ egg and $0.5 \%$ carboxymethyl cellulose), buckwheat lasagne (60\% buckwheat and $40 \%$ precooked rice flour, $30 \%$ egg), quinoa (Chenopodium quinoa, Willd; Anapqui, Asociacion Nacional de Productores de Quinua) and rice ('Vialone Nano'; Esselunga, Italy) were tested.

Flours were supplied by Mulino Pagani, Italy. Final products were manufactured in the Food Technology laboratory (Department of Food Science and Microbiology, Faculty of Agriculture, University of Milan).

All pasta dishes were cooked alone in water and then dressed with tomato sauce (GS, Italy).

Quinoa and rice were prepared as 'risotto' with aubergine, onion, zucchini and tomato sauce (all the ingredients were put together and cooked adding water).

The chemical composition of the foods determined by means of official chemical analysis (Association of Official Analytical Chemists, 1984) is shown in Table 1. Data on tomato sauce composition refer to the declared nutritional label.

The test meal consisted of a self-selection meal that allowed ad libitum consumption of a variety of different foods: baked lasagne, ham, cream cheese, crackers, chips, strawberry yoghurt, apricot jam tart, apple, banana, water. In experiment II, baked lasagne was omitted.

\section{Main procedure}

Three different experiments were conducted. A repeated measures design was followed within each experiment. The subjects, who had no knowledge of the aim of the study, were instructed to fast after 22.00 hours the previous evening, consume their standard breakfast before 08.30 hours each test day and to fast until they came to the laboratory. On arrival at 12.45 hours they were seated in a comfortable room.

In all the experiments, a preliminary session ('specific' satiety study) was performed in order to evaluate the amount of foods under study necessary to reach 'specific' satiety and to decide the large preloads. Subjects were instructed to eat each food served to excess, together with $500 \mathrm{ml}$ water (maximum amount), until they felt 'comfortably full' ('specific' satiety condition). After this test, the preloading paradigm strategy was used (Kissileff, 1984): each food (preload) was proposed in random order to the subjects at two different energy levels as the first course of a complete ad libitum test meal. Large and small

Table 1. Nutrient composition of foods $(\mathrm{g} / 100 \mathrm{~g})$ under study in experiments I, II and III

\begin{tabular}{|c|c|c|c|c|c|c|c|}
\hline & Food & Lipid & Protein & Carbohydrate & Fibre & Water & Energy $(\mathrm{kJ} / 100 \mathrm{~g})$ \\
\hline \multirow[t]{2}{*}{ Experiment I } & White bread & $2 \cdot 4$ & $12 \cdot 0$ & $55 \cdot 5$ & 3.5 & $24 \cdot 7$ & 1222 \\
\hline & Oat bread & $3 \cdot 1$ & $10 \cdot 3$ & $46 \cdot 3$ & $5 \cdot 7$ & $32 \cdot 6$ & 1063 \\
\hline \multirow{6}{*}{ Experiment $\mathrm{II}^{*}$} & Spaghetti & $0 \cdot 8$ & $13 \cdot 0$ & $20 \cdot 9$ & 0.0 & $64 \cdot 4$ & 599 \\
\hline & Oat spaghetti & $1 \cdot 6$ & 14.9 & $18 \cdot 4$ & 0.4 & $63 \cdot 6$ & 620 \\
\hline & Lasagne & 0.5 & $6 \cdot 8$ & 28.9 & 0.8 & $61 \cdot 8$ & 620 \\
\hline & $\mathrm{CMC}$ buckwheat lasagne & $1 \cdot 0$ & $5 \cdot 2$ & $25 \cdot 1$ & $2 \cdot 4$ & 64.5 & 548 \\
\hline & Buckwheat lasagne & 1.0 & $6 \cdot 6$ & $27 \cdot 8$ & $1 \cdot 1$ & 61.9 & 611 \\
\hline & Tomato sauce & $1 \cdot 7$ & $1 \cdot 2$ & 5 & - & - & 167 \\
\hline \multirow[t]{2}{*}{ Experiment III† } & Quinoa & $3 \cdot 8$ & 3.4 & $16 \cdot 9$ & 4.7 & 69.8 & 481 \\
\hline & Rice & 2.9 & 2.4 & 22.9 & 0.9 & 69.6 & 532 \\
\hline
\end{tabular}

CMC, carboxymethyl cellulose.

* In experiment II we reported separately the nutrient composition of cooked pasta samples and of tomato sauce. † In experiment III we reported the nutrient composition of cooked and dressed samples. 
preloads were selected in order to have two different and distant conditions. In particular, the large preloads approached the 'specific' satiety amount within a range of subjects' acceptability. Water consumption was not limited.

Intake was assessed by weighing foods and drinks before and after consumption. Information about desire to eat, fullness and satiety sensations were obtained from a satiety ratings questionnaire. Three questions ('How satiated do you feel?', 'How full do you feel?' and 'How great is your desire to eat?'), developed in a previous investigation (Porrini et al. 1995), provided useful information in discriminating between the different satiety conditions. Three unbroken isosceles triangles were used as scales and the ratings were expressed in $\mathrm{cm}^{2}$ of area. Satiety, fullness and desire to eat sensation ratings were expressed as the difference between the scores obtained after and before the consumption of the meal. After the consumption of foods, a score of pleasantness was also expressed.

\section{Experiment I}

The aim of this experiment was to study the effect of oat breads on subsequent food intake and feelings of satiety, in comparison with white bread, and to understand whether the consumption of bread as a midmorning snack could have a positive impact on energy intake.

The different satiating properties of the two types of breads

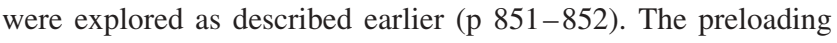
paradigm was applied using three rolls of bread as large preloads ( $224 \mathrm{~g}$ corresponding to $2736 \mathrm{~kJ}$ ( $654 \mathrm{kcal})$ for white bread; $240 \mathrm{~g}$ corresponding to $2554 \mathrm{~kJ}$ ( $610 \mathrm{kcal})$ for oat bread), and to one roll of bread as small preloads $(74 \mathrm{~g}$ corresponding to $904 \mathrm{~kJ}$ $(216 \mathrm{kcal})$ for white bread; $81 \mathrm{~g}$ corresponding to $862 \mathrm{~kJ}$ (206 kcal) for oat bread).

When bread was consumed as a midmorning snack, subjects came fasted from breakfast to the laboratory at 10.45 hours on two occasions and received the preload together with $500 \mathrm{ml}$ water. Between 11.00 hours and 12.45 hours they left the department, but they were not allowed to eat or drink anything else. The test meal was served at 12.45 hours.

When bread was consumed at lunch, subjects came fasted from breakfast to the laboratory at 12.45 hours.

In both conditions, they were told to eat and drink ad libitum and to fill in the questionnaire before and after eating.

\section{Experiment II}

The objective of this experiment was to analyse the satiating capacity of different oat, buckwheat and wheat pasta dishes (spaghetti and lasagne), with respect to their wheat counterparts.

The effect of pasta consumption on 'specific' satiety was evaluated only with spaghetti dishes as representative for pasta samples. The preloading paradigm strategy was also used in this experiment: subjects received, in random order, a portion of $500 \mathrm{~g}$ (large preload, corresponding to about $400 \mathrm{~g}$ cooked pasta and $100 \mathrm{~g}$ sauce) and a portion of $250 \mathrm{~g}$ (small preload, corresponding to about $200 \mathrm{~g}$ cooked pasta and $50 \mathrm{~g}$ sauce) of each pasta dish. Desire to eat, fullness and satiety were rated just before and immediately after consumption, and a score of palatability was also ranked.

In addition, a no-load condition (ad libitum test meal intake without any preload) was included in this experiment in order to evaluate the impact of the usual consumption of pasta as a first course of a meal on energy intake and satiety.

\section{Experiment III}

This experiment was undertaken to test the satiating effect of quinoa as compared with rice.

Subjects received the preloads, each at two different energy levels: the large preloads corresponded to $3852 \mathrm{~kJ}(920 \mathrm{kcal}$; $746 \mathrm{~g}$ ) for quinoa and to $4258 \mathrm{~kJ}$ ( $1017 \mathrm{kcal} ; 741 \mathrm{~g}$ ) for rice, while the small preloads corresponded to $1926 \mathrm{~kJ}$ (460 kcal; $376 \mathrm{~g}$ ) for quinoa and to $2127 \mathrm{~kJ}(508 \mathrm{kcal} ; 390 \mathrm{~g}$ ) for rice. They were instructed to eat the whole preload, and then to eat and drink the test meal ad libitum. A score of palatability was ranked. In this experiment, nine of the twelve subjects completed the study.

\section{Data analysis}

The data from ad libitum eating of foods in the 'specific' satiety condition (energy intake, weight intake) were computed by means of one-way ANOVA for repeated measures design using the type of food (formulation) as condition. A one-way ANOVA was also used to evaluate the pleasantness scores registered for the different foods.

In experiment I, energy, weight intake and satiety sensations were analysed by means of three-way ANOVA with bread formulation, preload energy level (small and large) and different time of consumption as factors.

In experiment II, energy, weight intake and satiety sensations were analysed by means of two-way ANOVA with pasta formulation and preload amount as factors. A subsequent comparison between the results obtained and those of the no-load condition was performed (one-way ANOVA).

In experiment III, energy and weight intake and satiety sensations were analysed by means of two-way ANOVA with type of food and preload energy level as factors.

For all the experiments, following a significant main effect in the ANOVA, individual means were compared using the least significant difference multiple range test. The criterion for significance was set at $P<0.05$.

For each food, the satiating efficiency was computed on the average values of the intakes as a function of load sizes for all subjects. The negative slope value of the intake-load function was considered as the satiating efficiency index (SEI; Porrini et al. 1995). SEI $<1.0$ are typical of products with low satiating efficiency; this means that the larger the preload the larger would be the amount of increase in the total energy intake (poor compensation). SEI $=1.0$ are typical of products whose consumption produces a perfect compensation of total energy intake. Products with SEI $>1.0$ are satiating; that is, the larger the preload consumed the lower the total energy intake.

\section{Results}

\section{Experiment I}

Table 2 summarises the energy intake and weight intake of water and breads in the 'specific' satiety condition. No significant difference was observed between white bread and oat bread.

The mean scores of pleasantness are reported in Table 3; all subjects rated the two breads similarly. 
Table 2. Energy intake (kJ) and weight intake (g) of water and foods in the 'specific' satiety condition

(Mean values and standard deviations)

\begin{tabular}{|c|c|c|c|c|c|c|c|c|c|}
\hline & \multirow[b]{2}{*}{ Food } & \multicolumn{2}{|c|}{ Weight intake } & \multicolumn{2}{|c|}{ Water intake } & \multicolumn{2}{|c|}{ Total intake } & \multicolumn{2}{|c|}{ Energy intake } \\
\hline & & Mean & SD & Mean & SD & Mean & SD & Mean & SD \\
\hline \multirow[t]{2}{*}{ Experiment I } & White bread & 317 & 70 & 402 & 59 & 719 & 171 & 3873 & 240 \\
\hline & Oat bread & 336 & 57 & 353 & 98 & 689 & 123 & 3571 & 145 \\
\hline \multirow[t]{2}{*}{ Experiment II* } & Spaghetti & 558 & 64 & 341 & 139 & 796 & 92 & 2860 & 79 \\
\hline & Oat spaghetti & 577 & 147 & 354 & 79 & 931 & 154 & 3056 & 186 \\
\hline \multirow[t]{2}{*}{ Experiment III† } & Quinoa & 800 & 181 & 439 & 181 & 1239 & 289 & 3852 & 209 \\
\hline & Rice & 801 & 147 & 401 & 156 & 1202 & 235 & 4258 & 188 \\
\hline
\end{tabular}

* In experiment II we reported the nutrient composition of cooked and tomato-dressed pasta samples.

†In experiment III we reported the nutrient composition of cooked and dressed samples.

Table 3. Palatability scores for foods consumed in experiments I, II and III (Mean values and standard deviations)

\begin{tabular}{|c|c|c|c|}
\hline & \multirow[b]{2}{*}{ Food } & \multicolumn{2}{|c|}{ Palatability } \\
\hline & & Mean & SD \\
\hline \multirow[t]{4}{*}{ Experiment I } & White bread & $6 \cdot 5$ & $1 \cdot 2$ \\
\hline & Oat bread & $5 \cdot 8$ & 0.9 \\
\hline & Spaghetti & 4.4 & 1.7 \\
\hline & Oat spaghetti & $5 \cdot 1$ & 1.7 \\
\hline \multirow[t]{3}{*}{ Experiment II } & Lasagne & $6 \cdot 7^{\star}$ & $1 \cdot 2$ \\
\hline & CMC buckwheat lasagne & 4.5 & 1.4 \\
\hline & Buckwheat lasagne & $4 \cdot 1$ & 1.4 \\
\hline \multirow[t]{2}{*}{ Experiment III } & Quinoa & $6 \cdot 3$ & 0.9 \\
\hline & Rice & $6 \cdot 8$ & 0.6 \\
\hline
\end{tabular}

CMC, carboxymethyl cellulose.

${ }^{\star} P<0.005$.

Table 4 summarises the energy and weight intake of the breads and the test meal under the different conditions.

Both the different time of preload consumption and the bread formulation did not affect weight and energy intake. However, it should be mentioned that oat bread consumption induced a different test meal energy intake depending on the preload energy level (the higher the preload the lower the test meal energy intake $)(P=0.022)$ particularly at 12.45 hours. On the contrary, test meal energy intake was not modulated by white bread preloads; thus, the higher the preload energy level the higher the total (preload plus ad libitum test meal intake) energy intake $(P=0.016)$, independently from the model of consumption (as snack or at 12.45 hours). This was confirmed by the different SEI observed for the two breads (Fig. 1(a)); 0.8 for oat bread and 0.2 for white bread, in both models of preload consumption.

No effect of the preload energy level was evidenced on weight intake.

As regards the variations of satiety sensations before and after the consumption of preloads, we did not observe an effect of bread formulation (data not shown). On the contrary, the preload energy level significantly affected fullness $(P=0 \cdot 002)$, desire to eat $(P=0.009)$ and satiety $(P=0.000)$; in particular, the large white bread preload induced a significant decrease of desire to eat and a significant increase of satiety and fullness sensations, compared with the small one. Furthermore, a significant effect of the type of preload consumption on the variation of satiety was noted $(P=0.017)$, as the satiety rating was significantly higher after the large oat bread consumed at 12.45 hours than after the large oat bread consumed as a snack.

\section{Experiment II}

Table 2 summarises the energy intake and weight intake of water and pasta samples in the 'specific' satiety condition. No significant difference was observed among the different pasta samples.

Table 4. Energy intake (kJ) and weight intake $(\mathrm{g})$ in the different conditions of experiment I (Mean values and standard deviations)

\begin{tabular}{|c|c|c|c|c|c|c|c|c|}
\hline & \multicolumn{4}{|c|}{ White bread } & \multicolumn{4}{|c|}{ Oat bread } \\
\hline & \multicolumn{2}{|c|}{ Large } & \multicolumn{2}{|c|}{ Small } & \multicolumn{2}{|c|}{ Large } & \multicolumn{2}{|c|}{ Small } \\
\hline & Mean & SD & Mean & SD & Mean & SD & Mean & SD \\
\hline Preload energy intake & 2736 & - & 904 & - & 2554 & - & 862 & - \\
\hline Preload weight intake & 224 & - & 74 & - & 240 & - & 81 & - \\
\hline \multicolumn{9}{|c|}{ Preload consumed as a snack } \\
\hline Test meal energy intake & 4107 & 372 & 4467 & 313 & 3651 & 250 & 4769 & 219 \\
\hline Total energy intake & $6845^{\mathrm{b}}$ & 372 & $5372^{\mathrm{a}}$ & 313 & $6205^{a, b}$ & 250 & $5631^{a, b}$ & 219 \\
\hline Total weight intake & 1239 & 366 & 1244 & 57 & 1237 & 366 & 1304 & 296 \\
\hline \multicolumn{9}{|c|}{ Preload consumed at 12.45 hours } \\
\hline Test meal energy intake & $3998^{a, b}$ & 367 & $4358^{a, b}$ & 166 & $3132^{\mathrm{a}}$ & 96 & $4693^{b}$ & 271 \\
\hline Total energy intake & $6732^{b}$ & 367 & $5263^{a}$ & 166 & $5686^{\mathrm{a}, \mathrm{b}}$ & 96 & $5556^{\mathrm{a}, \mathrm{b}}$ & 271 \\
\hline Total weight intake & 1094 & 187 & 1056 & 174 & 1136 & 213 & 1131 & 189 \\
\hline
\end{tabular}

${ }^{a, b}$ Mean values within a row with unlike superscript letters were significantly different $(P<0.05)$. 

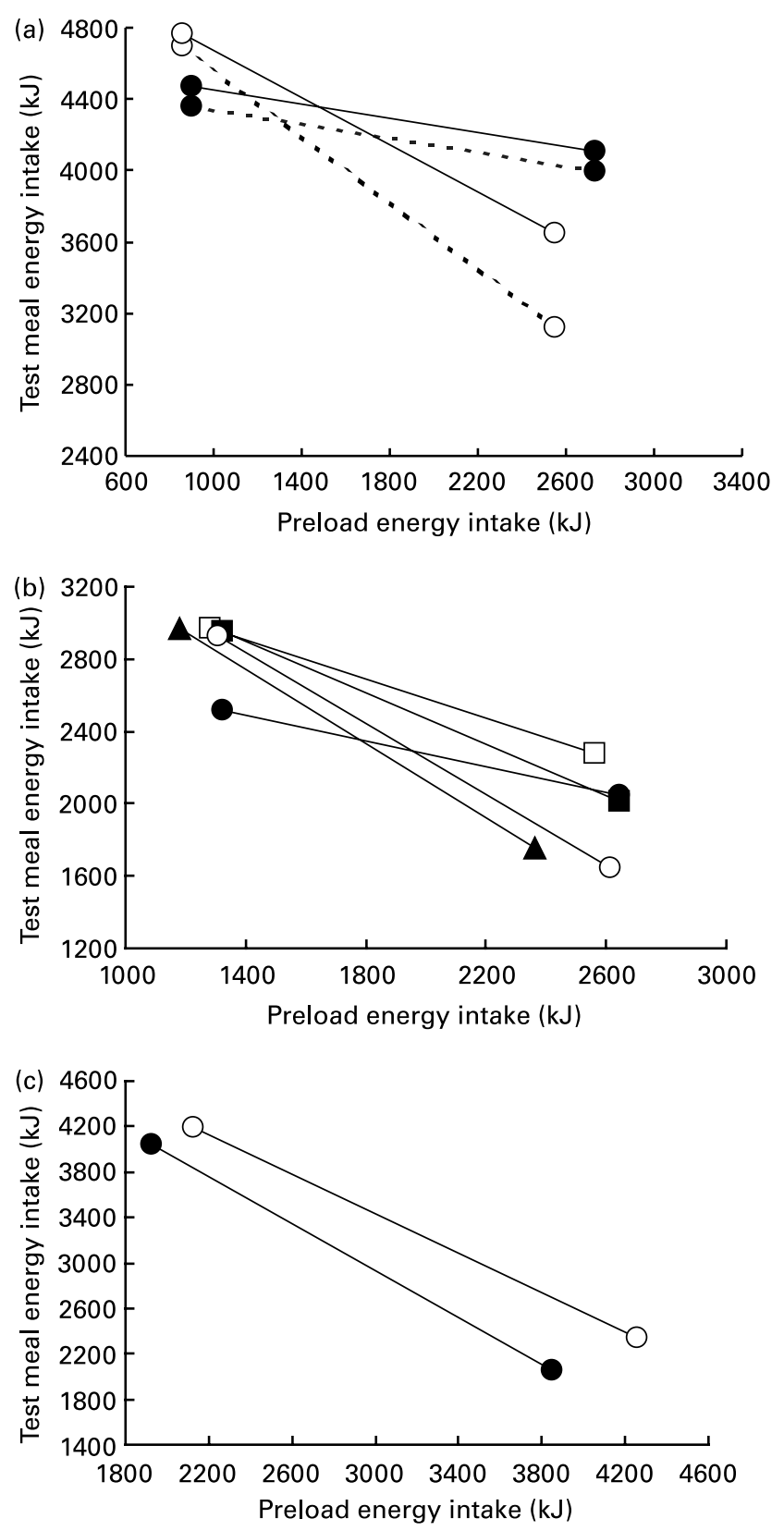

Fig. 1. (a) Intake-preload functions in experiment I for white bread (--•--; satiating efficiency index $(\mathrm{SEI})=0.2)$, white bread as a snack $(-\bullet-$; SEI $=0.2)$, oat bread (--O--; SEI $=0.9)$ and oat bread as a snack (-O-; $\mathrm{SEI}=0.7)$. (b) Intake-preload functions in experiment II for spaghetti (- $\square-$; $\mathrm{SEI}=0.5)$, carboxymethyl cellulose buckwheat lasagne $(-\Delta-; \mathrm{SEI}=1.0)$, buckwheat lasagne $\left(-O_{-} ;\right.$SEI $\left.=1.0\right)$, oat spaghetti $(-\square-$; SEI $=0.7)$ and lasagne (-๑; SEI $=0.4)$. (c) Intake-preload functions in experiment III for quinoa (-๑; SEI $=1.0)$ and rice $(-O-;$ SEI $=0.9)$.

In Table 3 pleasantness scores expressed for each type of pasta are shown. The statistical analysis showed that pasta formulation affected the pleasantness $(P=0 \cdot 000)$; in particular, subjects gave the highest score to lasagne.

Table 5 summarises the energy intake and weight intake of the pasta dishes and the test meal under the different conditions plus that of the no-load condition. Total energy intake with pasta dishes was always comparable with that in the no-load condition, with the exception of the small lasagne that induced significantly lower energy intake.
ANOVA on data obtained from the preloading paradigm did not show any effect of pasta formulation on total (preload plus test meal) energy and weight intake.

The energy level of pasta preloads affected the test meal energy intake $(P=0 \cdot 000)$; in fact, it was always lower after the large ones. As regards the total energy intake, a significant effect of the energy level of preload was observed only for spaghetti and lasagne $(P=0.006)$; the least significant difference multiple range test revealed that the large preloads of spaghetti and lasagne caused a significant increase in total energy intake compared with the small ones. Pasta SEI (Fig. 1(b)), calculated considering the two preload energy levels, demonstrated a low satiating efficiency (SEI $\leq 1 \cdot 0)$. In particular, the two types of buckwheat lasagne indicated a perfect compensation, whereas the lasagne SEI $(0 \cdot 4)$ indicated that the larger the preload the larger the amount of test meal intake.

As regards the total weight intake, a significant effect of the energy level of preload was observed $(P=0 \cdot 000)$, as the large oat spaghetti, carboxymethylcellulose buckwheat lasagne, buckwheat lasagne and lasagne preloads determined significantly higher total intake compared with the small ones. Furthermore, the total weight intake was similar to that of small preload conditions, but significantly lower than that after large preloads $(P=0 \cdot 002)$.

A significant effect of preload energy level on fullness $(P=0.000)$, desire to eat $(P=0 \cdot 000)$ and satiety $(P=0 \cdot 000)$ was also observed (data not shown).

\section{Experiment III}

Table 2 summarises the energy intake and weight intake of water, quinoa and rice in the 'specific' satiety condition. No significant difference was observed between quinoa and rice, and the mean scores of pleasantness (Table 3 ) were also comparable.

In Table 6 the means of test meal and total intake, expressed as energy content $(\mathrm{kJ})$ and weight $(\mathrm{g})$, are shown. Neither the type of food nor the preload energy level affected the total energy intake. Instead, a significant effect of the preload energy level was evidenced on both the test meal energy intake $(P=0 \cdot 000)$, and the total weight intake $(P=0 \cdot 042)$. In fact, the large preloads induced lower test meal energy consumption.

The load-intake function for the quinoa and rice preloads is reported in Fig. 1(c). The mean SEI calculated for both the foods was $1 \cdot 0$.

No significant effect of preload energy level on fullness, desire to eat $(P=0.000)$ and satiety was also observed (data not shown).

\section{Discussion}

\section{Experiment $I$}

Oat bran or oat fibre has achieved a very positive consumer image because of the health benefits associated with their consumption; it seems to reduce blood cholesterol, affect glycaemic response, delay gastric emptying and prolong satiety after a meal (Mälkki \& Virtanen, 2001). From our data, bread cannot be considered a satiating product; however, oat bread (SEI $=0.7,0.9)$ resulted in more satiating than white bread (SEI $=0 \cdot 2)$.

The main result of the present study regards the importance of the energy level of bread preloads on eating behaviour. This fact is particularly evident considering the SEI values; despite the fact that the mean total energy intake registered with the consumption of oat bread and white bread is comparable, the SEI indicates a 


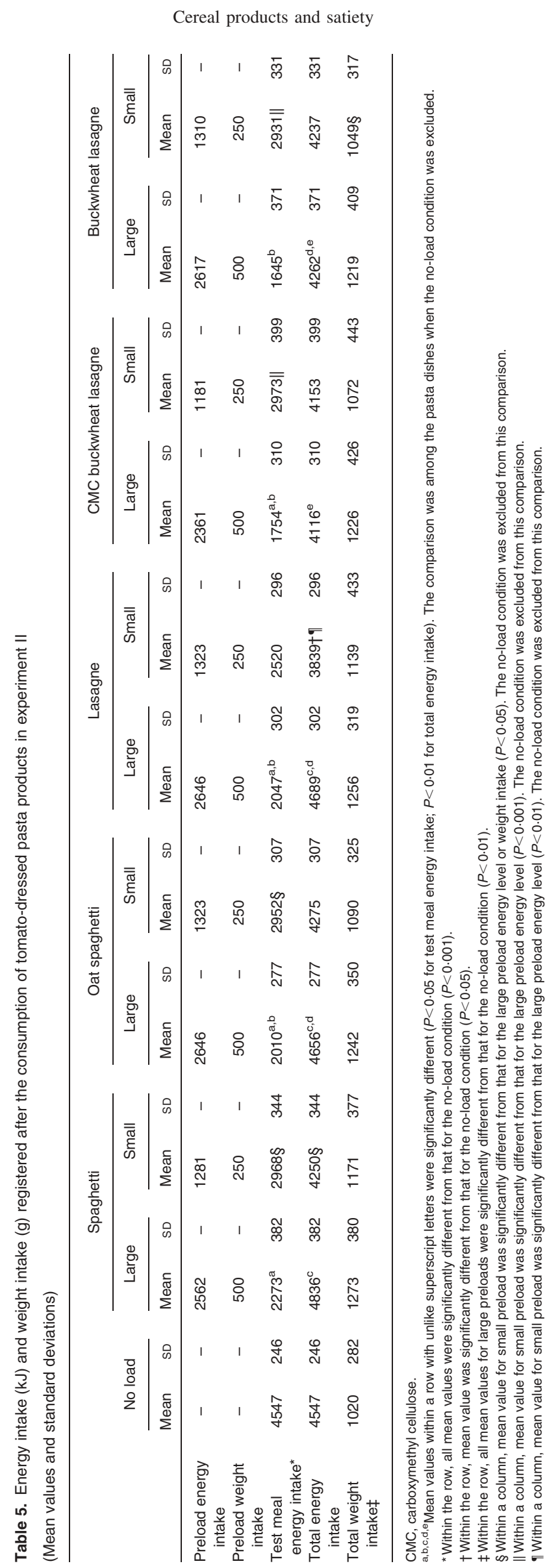


Table 6. Energy intake (kJ) and weight intake $(\mathrm{g})$ in the different conditions of experiment III

(Mean values and standard deviations)

\begin{tabular}{|c|c|c|c|c|c|c|c|c|}
\hline & \multicolumn{4}{|c|}{ Quinoa } & \multicolumn{4}{|c|}{ Rice } \\
\hline & \multicolumn{2}{|c|}{ Large } & \multicolumn{2}{|c|}{ Small } & \multicolumn{2}{|c|}{ Large } & \multicolumn{2}{|c|}{ Small } \\
\hline & Mean & SD & Mean & SD & Mean & SD & Mean & SD \\
\hline Preload energy intake & 3852 & - & 1926 & - & 4258 & - & 2127 & - \\
\hline Preload weight intake & 746 & - & 376 & - & 741 & - & 390 & - \\
\hline Test meal energy intake & 2060 & 334 & $4040^{*}$ & 439 & 2340 & 393 & $4195^{\star}$ & 409 \\
\hline Total energy intake & 5912 & 334 & 5966 & 439 & 6598 & 393 & 6322 & 409 \\
\hline Total weight intake & 1516 & 328 & 1441 & 338 & 1543 & 336 & 1395 & 203 \\
\hline
\end{tabular}

${ }^{*}$ For each food, mean value was significantly different from that for the large preload condition $(P<0.001)$.

†The lower preload weight intakes corresponding to 3852 and $4858 \mathrm{~kJ}$ with respect to those reported in Table 2 were due to a loss of water during the cooking procedure.

higher satiating efficiency of the former product. This means that by increasing oat bread consumption we have a decrease in subsequent energy intake, as compared with white bread. The consumption of three white bread rolls instead of one induced an increase in total energy intake of about $1473 \mathrm{~kJ}$; thus, a low satiating effect or appetising effect. Such an observation is supported by data published by Holt et al. (1995) which validated a satiety index score (ratio between the 120 min satiety response curve for $996 \mathrm{~kJ}(238 \mathrm{kcal})$ portion of test foods and the $120 \mathrm{~min}$ satiety response curve for $996 \mathrm{~kJ}$ ( $238 \mathrm{kcal})$ portion of reference bread) of common foods. The satiety index method was developed to rank the filling powers of equal-energy portions of common foods and to determine which nutrient combinations, sensory and physical factors, and food preparation methods can change the feeling of fullness responses. Comparing the satiety index of white bread with that of grain bread and wholemeal bread, it was found that white bread was the least satisfying. From this point of view, the intake of oat bread (with lower glycaemic index (Foster-Power et al. 2002) and higher fibre content with respect to white bread) may be advisable to modulate energy intake. It is suggested that slowly absorbed, low-glycaemic index foods may improve glucose tolerance at the second meal and also affect eating behaviour and satiety (Wolever et al. 1988; Liljeberg et al. 1999; Roberts, 2000; Lodwing, 2000; Wolever, 2000; Brand-Miller et al. 2002).

This may be of particular importance when considering the consumption of bread as a snack rather than for lunch. Meal patterning may influence physiological variables and eating behaviour (Schlundt et al. 1992; Porrini et al. 1997). There is evidence that snacks have poor satiating efficiency (Marmonier et al. 2002) and that the energy consumed from snacks between meals provides further energy to daily intake (Rolls et al. 2004). On the contrary, we hypothesised that the consumption of oat bread as a snack could have a positive impact on energy intake at a meal. In the present study, the model of consumption did not affect energy intake and differently from what expected; oat bread exerted the higher satiating effect when consumed for lunch.

\section{Experiment II}

Pasta is an important product in the Italian and Mediterranean diet. While the consumption of this product is advisable because of the low glycaemic responses (Granfeldt et al. 1994; Barkeling et al. 1995; Holt et al. 1996; Liljeberg et al. 1999), it has been suggested (Porrini et al. 1995) that pasta has low efficacy in reducing satiety. Thus, it would be more beneficial to use oat flour or buckwheat flours in order to obtain bulky and less refined foods. In particular, buckwheat (Fagopyrum esculentum) is an important source of many substances with high biological value (Bonafaccia et al. 2003), resistant starch and dietary fibre content (Skrabanja et al. 2001b). Moreover, an investigation designed by Skrabanja et al. (2001a) showed that buckwheat may be potentially used in the design of food with lower glycaemic index.

What emerges from the present investigation is that, from a general point of view, the consumption of pasta just before the test meal does not provide any contribution to the total energy intake when compared with the no-load condition. In fact, the energy introduced was comparable with that observed in the no-load condition. Among pasta dishes, spaghetti and lasagne were the least satiating products, while the formulations containing alternative crops (oat or buckwheat flours) resulted in the increase of the satiating power, as previously suggested.

Though designed with different aims, it seemed interesting to compare the different experiments with volunteers homogeneous in sex, age and eating habits. In particular, a comparison with the results of experiment I suggests that spaghetti and lasagne are more satiating than white bread. Furthermore, a lower energy intake was always registered after the consumption of pasta with respect to bread. This result may be attributed to the fact that to provide a similar energy level, the pasta preload weight was about two-fold higher than bread preload weight, a difference attributable to the lower energy density of pasta meals (Porrini et al. 1995; Poppit \& Prentice, 1996; Bell et al. 1998) due to the higher amount of water intrinsically bound. Furthermore, this result may be interesting, considering that spaghetti has been demonstrated to lower not only glucose and insulin responses, but also the serum triacylglycerol levels after the second meal (Liljeberg \& Björck, 2000).

\section{Experiment III}

In this last experiment we evaluated the potential exploitation of the alternative crop quinoa, which has been suggested as a recipe for GF foods, as no gliadin-like proteins have been assessed by immunochemical approaches (Berti et al. 2004a). In addition, comparing in vivo metabolic responses to quinoa and other GF foods, we found that quinoa represented a potential alternative for coeliac subjects. In addition, the data we obtained after the consumption of the different products suggested that quinoa 
induced a lower desire to eat and higher fullness and satiety sensations than the other GF foods (Berti et al. 2004b). Moreover, as its grains contain lysine-rich proteins, PUFA, micronutrients and vitamins (Chauhan et al. 1992; Ranhotra et al. 1993; Ruales \& Nair, 1993, 1994), mixing cereal grains with quinoa can enhance the nutritional value of the resultant product.

From the present study, the consumption of quinoa and rice as preloads did not produce a satiating effect (SEI of 1.0 and 0.9 , respectively). Furthermore, the higher total energy intake registered, with respect to the experiment II, may be explained considering the higher preload amounts consumed.

Interestingly, our subjects expressed a high palatability score for quinoa despite the fact that they were not normally consumers of this grain, indicating that quinoa could be appreciated in our traditional diet.

\section{Conclusion}

In general, the present results point out that:

Pasta and bread are not satiating products;

The addition of alternative crops can affect the satiating efficiency of the product;

The availability of large portions of foods may be one of the environmental influences associated with excess energy intake (Porrini et al. 1995, 1997; Rolls et al. 1998, 2002, 2004). In our experimental conditions, foods consumed in high amounts induced even more eating;

Eating cereal foods (for example, bread) as a snack does not seem to reduce energy intake at the subsequent meal;

Oat or buckwheat formulations and quinoa may represent a viable alternative to traditional cereal products as ingredients for special dietary use, particularly considering that they are good sources of functional substances and are GF foods.

\section{Acknowledgements}

The present study was partially supported by the National Ministerial Financial Grant COFIN 2000.

\section{References}

Abdel-Aal ESM \& Hucl P (2002) Amino acid composition and in vitro protein digestibility of selected ancient wheats and their end products J Food Comp Anal 15, 737-747.

Association of Official Analytical Chemists (1984) Official Methods of Analysis. Washington, DC: Association of Official Analytical Chemists.

Barkeling B, Granfeldt Y, Björck I \& Rössner S (1995) Effects of carbohydrates in the form of pasta and bread on food intake and satiety in man. Nutr Res 15, 467-476.

Bell EA, Castellanos VH, Pelkman CL, Thorwart ML \& Rolls BJ (1998) Energy density of foods affects energy intake in normal-weight women. Am J Clin Nutr 67, 412-420.

Bejosano FP \& Corke H (1999) Effect of Amaranthus and buckwheat proteins on the rheological properties of maize starch. Food Chem 65, 493-501.

Berti C, Ballabio C, Restani P, Porrini M, Iametti S \& Bonomi F (2004a) Immunochemical and molecular properties of proteins in Chenopodium quinoa. Cereal Chem 81, 275-277.

Berti C, Riso P, Monti LD \& Porrini M (2004b) In vitro starch digestibility and in vivo glucose response of gluten free foods and their gluten counterparts. Eur J Nutr 43, 198-204.
Blundell JE \& Burley VJ (1987) Satiation, satiety and the action of fibre of food intake. Int J Obesity 11, S9-S25.

Blundell JE, Green S \& Burley V (1994) Carbohydrates and human appetite. Am J Clin Nutr 59, 728S-734S.

Blundell JE, Hill AJ \& Rogers PJ (1988) Hunger and the satiety cascade - their importance for food acceptance in the late 20th century. In Food Acceptability, pp. 233-250 [DMH Thompson, editor]. Amsterdam: Elsevier Press.

Bonafaccia G, Galli V, Francisci R, Mair V, Skrabanja V \& Kreft I (2000) Characteristics of spelt wheat products and nutritional value of spelt wheat-based bread. Food Chem 68, 437-441.

Bonafaccia G, Marocchini M \& Kreft I (2003) Composition and technological properties of the flour and bran from common and tartary buckwheat. Food Chem 80, 9-15.

Brand-Miller JC, Holt SHA, Pawlak DB \& McMillan J (2002) Glycemic index and obesity. Am J Clin Nutr 76, 281S-285S.

Chauhan GS, Eskin NAM \& Tkachuk R (1992) Nutrients and antinutrients in quinoa seed. Cereal Chem 69, 85-88.

Coulter L \& Lorenz K (1990) Quinoa - composition, nutritional value, food applications. Lebensm WissTechnol 23, 203-207.

De Graaf C, De Jong LS \& Lambers AC (1999) Palatability affects satiation but not satiety. Physiol Behav 66, 681-688.

Delargy HJ, Burley VJ, O’Sullivan KR, Fletcher RJ \& Blundell JE (1995) The effects of different soluble:insoluble fibre ratios in breakfast on 24 h pattern of dietary intake and satiety. Eur J Clin Nutr 49, 754-766.

Delargy HJ, O'Sullivan KR, Fletcher RJ \& Blundell JE (1997) Effects of amount and type of dietary fiber (soluble and insoluble) on short-term control of appetite. Int J Food Sci Nutr 48, 67-77.

Di Cagno R, De Angelis M, Auricchio S, et al. (2004) Sourdough bread made from wheat and nontoxic flours and started with selected Lactobacilli is tolerated in celiac sprue patients. Appl Environ Microbiol 70, 1088-1096.

Foster-Powell K, Holt SHA \& Brand-Miller JC (2002) International table of glycemic index and glycemic load values. Am J Clin Nutr 76, 5-56

Gabrovská D, Fiedlerová V, Holasová M, Mašková E, Smrčinov H, Rysová J, Winterová R, Michalová A \& Hutař M (2002) The nutritional evaluation of underutilized cereals and buckwheat. Food Nutr Bull 23, S246-S249.

Granfeldt Y, Liljeber HGM, Drews A, Newman R \& Björck I (1994) Glucose and insulin responses to barley products: influence of food structure and amylose-amylopectin ratio. Am J Clin Nutr 59, 1075-1082.

Green SM \& Delargy HJ (1997) A satiety quotient: a formulation to assess the satiating effect of food. Appetite 29, 291-304.

Gutzmán-Maldonado SH \& Paredes-Lopez O (1999) Functional products of plants indigenous to Latin America: amaranth, quinoa, common beans, and botanicals. In Functional Foods. Biochemical \& Processing Aspects, pp. 293-328 [G Mazza, editor]. Lancaster, UK: Technomic Publishing Press.

Holm J \& Björck I (1992) Bioavalability of starch in various wheat-based bread products. evaluation of metabolic responses in healthy subjects and rate and extent of in vitro starch digestion. Am J Clin Nutr 55, 420-429.

Holt SHA, Brand Miller JC \& Petocz P (1996) Interrelationships among postprandial satiety, glucose and insulin responses and changes in subsequent food intake. Eur J Clin Nutr 50, 788-797.

Holt SHA, Brand Miller JC, Petocz P \& Farmakalidis E (1995) A satiety index of common foods. Eur J Clin Nutr 49, 675-690.

Holt SHA, Brand Miller JC \& Stitt PA (2001) The effects of equal-energy portions of different breads on blood glucose levels, feelings of fullness and subsequent food intake. J Am Diet Assoc 101, 767-773.

Holt SHA, Delargy HJ, Lawton CL \& Blundell JE (1999) The effects of high-carbohydrate vs high-fat breakfasts on feelings of fullness and alertness, and subsequent food intake. Int J Food Sci Nutr 50, 13-28.

Hughes E, Cofrades S \& Troy DJ (1997) Effects of fat level, oat fibre and carrageenan on frankfurters formulated with 5, 12 and $30 \%$ fat. Meat Sci 45, 273-281 
Kim SL, Kim SK \& Park CO (2004) Introduction and nutritional evaluation of buckwheat sprouts as a new vegetable. Food Res Int 37, 319-327.

Kissileff HR (1984) Satiating efficiency and a strategy for conducting food loading experiments. Neurosci Biobehav Rev 8, 129-135.

Liljeberg HGM, Åkerberg AKE \& Björck IME (1999) Effect of the glycemic index and content of indigestible carbohydrates of cereal-based breakfast meals on glucose tolerance at lunch in healthy subjects. Am $J$ Clin Nutr 68, 647-655.

Liljeberg HGM \& Björck IME (1994) Bioavailability of starch in bread products. Postprandial glucose and insulin responses in healthy subjects and in vitro resistant starch. Eur J Clin Nutr 48, 151-163.

Liljeberg HGM \& Björck IME (2000) Effects of low-glycaemic index spaghetti meal on glucose tolerance and lipaemia at a subsequent meal in healthy subjects. Eur J Clin Nutr 54, 24-28.

Lodwing D (2000) Dietary glycemic index and obesity. J Nutr 130, 280S-283S.

Mälkki Y \& Virtanen E (2001) Gastrointestinal effects of oat bran and oat gum. A review. Lebensm WissTechnol 34, 337-347.

Marmonier C, Chapelot D, Fantino M \& Louis-Sylvestre J (2002) Snacks consumed in a nonhungry state have poor satiating efficiency: influence of snack composition on substrate utilization and hunger. Am J Clin Nutr 76, 518-528.

Ogungbenle HN (2003) Nutrition and functional properties of quinoa (Chenopodium quinoa) flour. Int J Food Sci Nutr 54, 153-158.

Poppit SD \& Prentice AM (1996) Energy density and its role in the control of food intake: evidence of metabolic and community studies. Appetite 26, 153-174.

Porrini M, Crovetti R \& Testolin G (1995) Evaluation of satiety sensations and food intake after different preloads. Appetite 25, 17-30.

Porrini M, Santangelo A, Crovetti R, Riso P, Testolin G \& Blundell JE (1997) Weight, protein, fat, and time preloads affect food intake. Physiol Behav 62, 563-570.

Raben A, Tagliabue A, Christensen NJ, Madsen J, Holst JJ \& Astrup A (1994) Resistant starch: the effect on postprandial glycemia, hormonal response, and satiety. Am J Clin Nutr 60, 544-551.

Ranhotra GS, Gelroth JA, Glaser BK, Lorenz KJ \& Johnson DL (1993) Composition and protein nutritional quality of quinoa. Cereal Chem 70, 303-305.

Ranhotra GS, Gelroth JA, Glaser BK \& Lorenz KJ (1995) Baking and nutritional qualities of a spelt wheat sample. Lebensm WissTechnol 28, $118-122$.

Roberts S (2000) High-glycemic index foods, hunger, and obesity: is there a connection? Nutr Rev 58, 163-169.

Rolls BJ, Castellanos VH, Halford JC, Kilara A, Panyam D, Pelkman CL, Smith GP \& Thorwart ML (1998) Volume of food consumed affects satiety in men. Am J Clin Nutr 67, 1170-1177.

Rolls BJ, Morris EL \& Roe LS (2002) Portion size of food affects energy intake in normal-weight and overweight men and women. Am J Clin Nutr 76, 1207-1213.
Rolls BJ, Roe LS, Kral TVE, Meengs JS \& Wall DE (2004) Increasing the portion size of a packaged snack increases energy intake in men and women. Appetite 42, 63-69.

Ruales J, de Grijalva Y, Lopez-Jaramillo P \& Nair BM (2002) The nutritional quality of an infant food from quinoa and its effect on the plasma level of insulin-like growth factor-1 (IGF-1) in undernourished. Int $J$ Food Sci Nutr 53, 143-154.

Ruales J \& Nair BM (1993) Content of fat, vitamins and minerals in quinoa (Chenopodium quinoa, Willd) seeds. Food Chem 48, 131-136.

Ruales J \& Nair BM (1994) Effect of processing on in vitro digestibility of protein and starch in quinoa seeds. Int J Food Sci Technol 29, 449-456.

Schlundt DG, Hill JO, Sbrocco T, Pope-Cordle J \& Sharp T (1992) The role of breakfast in the treatment of obesity: a randomized clinical trial. Am J Clin Nutr 55, 645-651.

Singh N \& Smith AC (1997) A comparison of wheat starch, whole wheat meal and oat flour in the extrusion cooking process. J Food Eng 34, $15-32$.

Skrabanja V, Elmståhl Liljeber GM, Kreft I \& Björck I (2001a) Nutritional properties of starch in buckwheat products: studies in vitro and in vivo. J Agric Food Chem 49, 490-496.

Skrabanja V, Kovac B, Golob T, Elmståhl GM, Björck I \& Kreft I (2001b) Effect of spelt wheat flour and kernel on bread composition and nutritional characteristics. J Agric Food Chem 49, 497-500.

Størsrud S, Hulthén LR \& Lenner RA (2003) Beneficial effects of oats in the gluten-free diet on adults with special reference to nutrient status, symptoms and subjective experiences. Br J Nutr 90, 101-107.

Stubbs RJ, Mazlan N \& Whybrow S (2001) Carbohydrates, appetite and feeding behavior in humans. J Nutr 131, 2775S-2781S.

Valencia S, Svanberg U, Sandberg A-S \& Ruales J (1999) Processing of quinoa (Chenopodium quinoa, Willd): effects on in vitro iron availability and phytate hydrolysis. Int J Food Sci Nutr 50, 203-211.

Westerterp-Plantega MS, Rolland V, Wilson SAI \& Westerterp KR (1999) Satiety related to $24 \mathrm{~h}$ diet-induced thermogenesis during high protein/ carbohydrate $v s$ high fat diets measured in a respiration chamber. Eur $J$ Clin Nutr 53, 495-502.

Wolever TMS (2000) Dietary carbohydrates and insulin action in humans. Br J Nutr 83, S97-S102.

Wolever TMS, Jenkins DJA, Ocana AM, Rao VA \& Collier GR (1988) Second-meal effect: low-glycemic-index foods eaten at dinner improve subsequent breakfast glycemic response. Am J Clin Nutr $\mathbf{4 8}$, $1041-1047$.

Yilmaz I \& Dağhoğlu O (2003) The effect of replacing fat with oat bran on fatty acid composition and physicochemical properties of meatballs. Meat Science 65, 819-823.

Zieliński H \& Kozlowska H (2000) Antioxidant activity and total phenolics in selected cereal grains and their different morphological fractions. J Agric Food Chem 48, 2008-2016. 